\title{
Identification of Prevailing Roles to Which Tunisian Cooperative Teachers (CT) Attach a Big Importance in Accompanying Teacher Students (TS)
}

\author{
Hasan Melki, Mohamed Sami Bouzid, Aymen Hawani, Maher Mrayeh, Nizar Souissi \\ Higher Institute of Sport and Physical Education, Tunis, Tunisia \\ Email: hmelki@yahoo.fr
}

Received 25 April 2016; accepted 17 June 2016; published 21 June 2016

Copyright (C 2016 by authors and Scientific Research Publishing Inc.

This work is licensed under the Creative Commons Attribution International License (CC BY). http://creativecommons.org/licenses/by/4.0/

(c) (i)

\section{Abstract}

Training experience is an important part in the initial training of future teachers of Physical education (PE). The practice part of training is ensured at the same time by a university professor (UP) and a cooperative teacher from the school environment (CT). This latter ensures the teacherstudent's training, supervision and evaluation. He is usually selected according to his experience, his skills and his professional qualities. However, the recruitment of these mentors is considered as a serious challenge, since in Tunisia each teacher has the choice of being a mentor. Thus, it is important to have a better insight of the prevailing cooperative roles to which the Tunisian cooperative teachers grant the highest significance. This study has been achieved in the framework of a preparatory training to professional life for the teaching of physical education. It consists in an exploratory research. In order to discern the cooperative teachers' perceptions toward their contribution in the training of teacher-students, we have performed semi-directed interviews with 5 cooperative teachers. On that account, the interview analysis results highlight five major roles to which the cooperative teachers attribute a huge importance; 1) checking the planning quality of the courses supplied by the teacher-student; 2) observing the proceeding of the unfolding of the period; 3) urging the teacher-student to assume his responsibility; 4) assisting him to find solutions and finally; 5) exchanging ideas with the teacher-student.

\section{Keywords}

Teacher-Student (TS), Cooperative Teacher (CT), Physical Education (PE), Exploratory Research, Initial Professional Training, Accompaniment 


\section{Introduction}

In general, initial professional training considers work experience in concrete situations as a constitutive element for the development of professional skills and identity. For most people, initial training has an alternative function by creating "practice areas" through sending students to trainings in educational institutions.

The transformations of training programs for the teaching of physical education in Tunisia shows the importance granted to the training of teacher-students (TS) in order to improve teaching quality. Indeed, new requirements of initial training highlight the importance of a long-term and better-framed practical training in PE teaching which takes its foundations from a real partnership between university and school environment (Bali, 2005). A special care is given to the practical training aspect in PE teaching. This new trend stems from the necessity for future teachers of being competent as soon as they get their university degree. Consequently, the cooperative teachers' role (CT) for these future teachers acquires from then on an accrued importance. The functions linked to this Cooperative task are often defined as being very intricate and difficult (Metcalf, 1991; Rousseau, Courcy, \& Boutet, 2002).

For Lamy (2005), training by alternation represents one of the powerful levers of professionalization, by bringing a reflexive dimension, the possibility of experience confrontation and knowledge sharing. In Tunisia teachers referred to as cooperative teachers attend to each student during the whole year to induce him to live the alternation between the training institute and trainings in an integrative perspective (Bennour, 2013). Several accompaniment models are presently identified in an attempt to define the accompanist's position.

As much in the training programs of PE teaching as in the whole set of training programs in education, training, which is the milestone of initial training, is conceived to provide authentic and genuine experience in school environment (Bower \& Bonnett, 2009). Students give a primordial importance and a huge credibility to these trainings (Belton, Woods, Dunning, \& Meegan, 2010) and they consider these moments as the best and the most significant of initial training, in addition to being a crucial experience in their professional career (Boudreau, 2009; Desbiens, Borges, \& Spallanzani, 2009; Nichols, 2011). More specifically, training in physical education would allow establishing trainees' confidence in class management, planning, and teaching, social-izing with colleagues and students and interventions on behalf of students with special needs (Nichols, 2011). Even though several elements contribute to make a training successful, the cooperative teacher is recognized as being an essential actor with a huge influence on teacher-students' training quality (Gervais \& Desrosiers, 2005; Portelance, 2010). The Cooperative teacher has a significant impact on teacher-students' learning, professional development and on the success of a training (Boudreau, 2009; Peterson, Valk, Baker, Brugger, \& Hightower, 2010). Indeed, the cooperative teacher might allow teacher-students to live concrete teaching experiences by offering them the opportunity to teach their pupils. The cooperative teacher might also try to control the environment in order to provide future teachers with favorable conditions for their success by making sure, for instance, that the course is well-prepared, that the teaching material is available and that the students are ready to learn. In the same way, the moments of the cooperative teacher's observation represent, for teacher-students, modeling experiences which allow self-evaluation of their own performance. Besides, the Cooperative teacher's positive feedback will probably convince trainees of their efficiency in teaching Physical Education. In the eyes of a teacher-student, the cooperative teacher is a guide, and even a companion who walks by your side and behind you assuming the role of a witness, more at a distance. Researchers performed on the Cooperative teacher's professional identity on field show that associate teachers (cooperative teachers) hardly identify themselves to the role of a trainees' educator (Boudreau, 2001; Durand, 2000; Pelpel, 2003). In other words, the associate teacher considers himself more as an experienced teacher than a teacher-student's mentor (Gohier, Bouchard, Anadon, Charbonneau, \& Chevrier, 2002). Durand's (2000) study shows that some teachers are in difficulty as soon as they find themselves performing the function of associate teachers (Pelpel, 2003). Finally, Clerc (1998) states that a good teacher is not necessarily a good practicing-mentor (cooperative teacher). The teacher's skills and those of a practicing-mentor (i.e. cooperative teacher) are not of the same kind. Therefore, being a teacher is not enough to become a cooperative teacher.

As demonstrated by the above-mentioned works, the cooperative teacher seems to have a huge impact on trainees' development (Desbiens et al., 2009). He plays a key role in professional training in the technical field. (Portelance, 2010) and his influence on future teachers is perhaps greater than any other mentor (Guyton \& McIntyre, 1990). On that account, for them, he is considered as a model who has an impact on their attitudes and their behavior, as well as on the conception which they have on teaching and on their privileged teaching style. 
(Chaliès, Ria, Bertone, Trohel, \& Durand, 2004). Consequently, it is essential to better know the prevailing roles in accompaniment for which Tunisian cooperative teachers give the highest level of importance.

\section{Literature Review}

In the process of training future Tunisian teachers, the role of pedagogical training as a practical training is as important as that of theoretical courses acquired inside higher education Institutes. But most often, these two training components evolve independently, without necessarily having coherence or cohesion between them and also without having any tight collaboration between university professors and cooperative teachers in school establishments. Researches in teacher training show that the success of teacher training is generally dependent on the nature of associate teachers' (cooperative teachers) intervention during the trainee's supervision (Guyton \& McIntyre, 1990). Recent researches using teachers' perceptions as a source of information (Arrighi, 1983) have concluded that there is a tight link between what the teachers think and how they behave in a teaching situation (Shulman \& Lanier, 1977).

Seen the importance of pedagogical training and the determinant role of the cooperative teacher in the training of future teachers, the investigation of his conceptions is very appreciated by researchers in the field of education since many of them are convinced of the existence of a relation between a teacher's conceptions and his planning as well as his educative decisions and his practices (Deaudelin et al., 2005). Fenstermacher (1979) states that teachers' perceptions concerning their efficiency and their behavior provide the basis for their beliefs and their action. All the pertinence of this issue is found in Tunisia. For the Tunisian Cooperative teacher his responsibility in training future teachers is a major challenge to take. Given the importance of practical training, the cooperative teachers have to assume an important training role. Yet, it is proved that training programs in education are very little concerned about the role of cooperative teachers and their preparation to assume this role.

To implement an accompaniment tightly linked to a professional training, it is preferable that cooperative teachers share the same conception of their role as an accompanist of teacher-students, which makes up the first major challenge and this because most of the cooperative teachers do not conceive their role within the process of professionalism in the same way, (Correa Molina, 2008). Even if the teacher-student is responsible of his training, he needs support. The Cooperative teacher assumes the responsibility of acting as a teacher-student's mentor. One crucial question to ask concerns whether he adheres to this idea and whether he feels able to perform the duties confided to him. One of the most important deficiencies existing in the framework of practical training in education consists in the supposition that all practicing teachers are ready to assume the role of Cooperative students without prior preparation or training, but only from their own experience on field or in the gymnasium. More specifically, researches in the field of the mentors' professional identity reveal that cooperative teachers hardly identify themselves to the role of a teacher student's mentor (Pelpel, 2003). In other words, the Cooperative teacher thinks of himself as an experienced teacher rather than a teacher-student's mentor (Gohier, Bouchard, Anadon, Charbonneau, \& Chevrier, 2002).

Tannehill and Zakrajsek (1988), have revealed that some cooperative teachers make few teaching remarks to the teacher-student and give little feedback. Teachers seem little inclined to give a feedback or even look incapable of doing so even after formal sessions of observation of the teacher-student (McNally, 1997). On the other hand, a teacher can define his profession in many ways, often from his own viewpoint. Indeed, according to the definition he adopts and the conception that he makes of his role, he would tend to see only certain types of the teacher-student's behavior and accompany him according to this conception. Therefore, cooperative teachers often undergo a difficulty in getting out of their shell as teachers to keep company and take care of the teacher-student outside technical knowledge (Desbiens, Spallanzani, \& Borges, 2013). Dodds (1985), demonstrates that the Cooperative teacher is the person who exerts the highest influence on the student during training. On the other hand, Barnes (1981) has shown that selecting cooperative teachers is one of the most neglected aspects in educational training programs.

A study conducted by Petignat (2008), brings to light the teacher-student's perceptions concerning the influence of training. According to this research, teacher-students do not perceive the training as the first element at the origin of their educational learning. The teacher-student's personal history, teaching practice in the classroom, and even university training seem to be, for him, at the origin of his professional acquisition. Moreover, for Martin (2002), cooperative teachers would transmit very little of their knowledge to the teacher-student. 
Teacher-students rely on the training and on the cooperative teachers to get the maximum of knowledge which would be useful for their teaching practice. According to many researchers (Guyton, 1989), the biggest majority of cooperative teachers have little experience in the supervision of teacher-students and they all agree to admit that they need preparation in supervision. In addition to the lack of training in supervision, communication between university professors and practicing teachers seems to be almost inexistent. Locke (1984) and Dodds (1985), highlight the fact that cooperative teachers and university professors have different expectations and perceptions concerning each one's role in the training of a future teacher.

These statements in relation to the role and practices of the cooperative teachers' accompaniments do not emerge without a reason. Given the fact that an CT's role is complicated, it is not surprising that expectations towards him are hard to satisfy. In front of this uneasy issue concerning the CT's identity as a teacher-student's mentor, one must wonder about the link between the CT's accompaniment practices and his dominant roles as a mentor.

\section{Research Objective}

It is a descriptive study whose objective consists in identifying-according to cooperative teachers (CT)-the conception attributed to them in relation to the dominating accompaniment roles to which they give the highest importance.

Our current study is based on an inductive quantitative approach which aims at replying to two questions: (1) What are the dominating roles which cooperative teachers prefer in accompanying teacher-students? (2) How do cooperative teachers identify their accompaniment practices in pedagogical training?

\section{Methods}

This current study has been achieved in the framework of the preparation and training to professional life performed by students at the end of initial educational training. We have used the method of interview survey.

The questioned participants (Hedy, Aymen, Karima, Lotfi and Marwa [pseudonyms]) are cooperative teachers $(n=5 ; 3$ men and 2 women). The participants' age is $40 \pm 5$. The main criteria applied for the sampling consisted in the participants' having at least five years of experience as pedagogical advisors. We have met with each cooperative teacher individually to show them and explain the research procedure (Table 1).

\section{Procedures}

We have elaborated an interview guide particularly for this study. It is made mainly of six questions each one of them having by-questions that could be asked if the contents were not covered spontaneously by the participants. These questions have allowed to collect data on the way pedagogical accompaniment is performed by cooperative teachers according to their own point of view. In order to establish the most adequate atmosphere, the location and interview hours have been set in relation to the participants' availability.

The interview has been validated in advance in the presence of three teachers who have monitored teacher-students in PE and who teach at the Higher Institute of Sport and Physical Education in Tunis We have asked them to make a critical reading on the clarity and pertinence of statements and give any comments and/or suggestions which they deem appropriate and necessary.

The interview data were collected par audio recording by means of a Dictaphone. The content of each interview has been rewritten integrally by the researchers in the form of verbatim. Then, after many readings, we have coded the texts in meaningful units. According to Baribeau (2009), "Coding is a heuristic approach where

Table 1. Participants profiles.

\begin{tabular}{ccc}
\hline Names (pseudonyms) & Gender & Years of experience \\
Hedy & Male & $5-10$ years \\
Aymen & Male & $10-15$ years \\
Karima & Female & 5 years \\
Lotfi & Male & 5 years 10 \\
Marwa & Female & 15 - 20 years \\
\hline
\end{tabular}


data are linked to ideas on the data in order to rearrange all the passages under the same heading (p.140)".

Data analysis has been achieved by the method of content analysis. An analysis grid has been conceived from predetermined categories in the interview guide and on the other hand by the participants' emergent discourse categories. Once the interview content was recorded, it is then submitted to a qualitative analysis inspired from Spradley's technique of semantic relation (1980).

\section{Results and Discussion}

We start this section by describing the cooperative teachers' perception toward the roles they consider playing in the training of teacher-students according to their importance. Then, we present the conceptions of interviewed persons concerning the significance of these tasks during the teacher-students' training practice.

\subsection{Check Planning Quality of the Courses Provided by Teacher-Students}

The five participants describe an important role played by Cooperative teachers, namely the pedagogical role. They consider that all the suggestions and instructions aiming at improving the teaching and learning process should stem from them. All the participants, without exception, consider their role as a pedagogical component. Indeed, cooperative teachers mention the need to constantly check whether future teachers possess and apply the program as it has been planned for them. Therefore, many participants associate their responsibility of improving the training and learning process with the fact of reviewing the details with training students, by explaining the objectives item by item until conclusion going through the progressive steps of a PE session.

[...] It is necessary to discuss with the teacher-student about what has been done in the session and whether the objective has been achieved or not. If the objective is not achieved, we show him his errors (Aymen, lines 10 - 12)

[...] The aim of accompaniment is to have a full understanding of the teacher-student's strengths, encourage him and address his weaknesses. It is also to carry his knowledge to something more concrete then urge him to become more autonomous.

[...] often find myself repeating to my trainees: "Adopt a rational approach in your planning from the start and stick to it" (Karima, lines 14 - 16)

According to participants, the pedagogical role of a Cooperative teacher requires from him to be an expert in didactics. Indeed, they consider that the cooperative teacher's duty is to assist future teachers and lead them to acquire knowledge and skills which shall allow them to deal with the program in the best conditions. To attain this goal, the Cooperative teacher must master various methods which are appropriate to the teaching of PE in order to educate future teachers. A future teacher has to be in touch with the new methods which are likely to facilitate pupils' learning. It is someone who should manage to perceive the capacities of future teachers.

[...] A good knowledge of the physical activities to teach and the teaching methods is required. For instance, at a certain era in the past, physical activity was taught one way and now it is taught another way, completely different from the past due to scientific progress in physical activity and sports. (Marwa, lines 25 - 27)

In the opinion of participants doing this work correctly requires from cooperative teachers to be endowed with enough experience, which allows them to accomplish their mission efficiently, obtain positive results and satisfy needs.

[...] I think that he must be competent. A cooperative teacher is an expert in his field. He is a dynamic person worried about his duty. (Hedy, lines 29 - 31)

They go on in their statement by stating that a cooperative teacher who is eager about helping future teachers to improve their performance must be endowed with a recognized and authentic competence since it is the fountain for teacher-students to quench their thirst for knowledge and collect their need for learning.

[...] If we want to help someone improve, we have to be equipped in advance. These tools help the cooperative teacher in shaping the teacher-student and in reaching his objectives. However, he should be given some freedom. I monitor him, yes but I cannot be tracking him all the time, sticking to his footsteps. I would appreciate that my trainees take initiatives. It boosts their self-confidence. (Lotfi, lines 4 - 7).

\subsection{Observe Teacher-Students}

To prepare an observation, our cooperative teachers use different approaches. Lotfi has several ways of doing things. Sometimes he makes a systematic observation and supervises all the progress of the session. He also 
concentrates on specific training criteria and sometimes focuses on something precise, at the request of the teacher-student or in connection with an existing issue in order to find a solution.

[...] Personally, I plan all my work. I prepare my observation grids which help me to identify the teacherstudent's conduct. Thus, I can intervene with precision on the skills and strategies adopted by the teacherstudent and bring efficient modifications if necessary. Observation grids could serve as a reference to the teacher-student later on. (Lotfi, line 22)

Hedy and Karima rely entirely on the specific training criteria. According to them, this observation would allow the teacherto analyze his practice and make some progress. They also use planning grids to check if what the teacher-student has planned theoretically corresponds or not to what he actually achieved during the session. For them, the purpose of these observations is simply to verify if the grid criteria are reached or taken into consideration.

[...] I observe and take note of each of the criteria. That's why I use an observation grid to see if the trainee has predicted to do correspond to what he achieved actually. (Hedy, line 19)

[...] Generally, I keep in my grid of observation a space intended to the pupil's behavior and another space intended to the teacher-student's conduct (Karima, line 22)

Finally, Aymen also uses an observation grid. He always uses speciific criteria. For him, the purpose of observation is to see how the teacher-student acts according to his professional posture, his skills, his know-how and his knowledge of the world.

[...] On the whole, I'd say that the pupil's behavior reflects the teacher-student's behavior and attitude. Well, this is what I often manage to observe in my experience with teacher-students. (Karima, line 30)

Three of our cooperative teachers privilege the manner of observing presented by Py and Leduc (2008) which is based on the grid of Training specific criteria. Indeed, Hedy and Aymen follow these authors' approach since they intendedly avoid focusing on the teacher. Indeed, they are also concerned with the pupils. Lotfi gets nearer to the idea stipulating that some freedom shall be allowed and grids are not strict laws as they vary the type of observation according to situations. Our participant Hedy joins Malderez et Bodoczky (2009) on the fact that observation is useful to allow the trainee to make his self-analysis because he is the first person who can evaluate his acts.

\subsection{Urge the Teacher-Student to Assume His Own Responsibility}

When asking cooperative teachers, they underlined the importance of this fundamental parameter and they estimated to classify it in third position as to its importance in the training of teachers. The five interviewed cooperative teachers agree to say that accompaniment corresponds first of all to pushing and urging the teacher-student to ponder on his teaching task.

[...] Taking my own experience as a reference, I would give advice and solutions to make things better. (Hedy, lines 20 - 21)

Indeed, Hedy and Marwa expressed their desire to push the trainee to be aware of the issues he may face during the process of a PE session.

Aymen and lotfi explain that the teacher-student is in real situation when he teaches. Therefore, it is his duty to manage and show his skills in such a situation so that his pupils can learn.

[...] It is the teacher-student who informs us what he has assimilated or not. (karima, line 23)

[...] We must urge the teacher-student to be involved and try to find a solution with him in order to reformulate the objective and determine an approach to follow in order to solve this situation. (Marwa, lines 20 - 22).

For Karima, it is easier to monitor a teacher-student who would admit his weaknesses and suggest himself solutions. We notice then that the five cooperative teachers are aware of the role of responsibility granted to the teacher-student in front of his quality of teaching. However, we can observe a similitude in the way cooperative teachers react; In fact, cooperative teachers accompany the teacher-student according to what they have planned. This implies that, in accopaniment, a cooperative teachertakes into account the didactic conception prepared by the Teacher-student and intervenes accordingly. In fact, it is the teacher-student who draws the c ooperative teacher's attention on the situations on which he wants to work and according to his own experience (Charlier, 1998).

\subsection{Help Teacher-Students to Find Solutions}

Respondents describe accompaniment as a process centred on collaboration. They state that accompaniment 
must be prepared with the Teacher-student's participation. In their opinion, cooperative teachers are capable of sharing their experience with the teacher-student within a team spirit. For them, the fact of sharing their experience with teacher-students seems to be a good means to determine the objective of accompaniment.

The issue is raised when the teacher-student is faced with a difficulty and his session does not work well. All the more if he does not react or implement anything to get him out of trouble. If this latter is conscious of the problem and he suggests remedial work always in the framework of a mutual collaboration, the teacher-student will not suffer any incidence. On this topic, Marwa deals with the difficulty encountered by the teacher-student as a means to learn. In so far as the same problem does not occur again very often, it might be beneficial in the training progress: Learning through error analysis.

[...] I often use the difficulties encountered by my trainees and their errors to build up new learning situations. Indeed, I reckon the teacher-student can learn to overcome his errors in other similar situations providing he becomes aware of them (Marwa, lines 15 - 18)

Hedy considers that the first thing to do is to let the teacher-student assume his responsibilities in front of difficulties. He has to be aware of the problem he faces. He adds that, if the situation is redundant, this may imply that the training is not valid. From one difficulty, he underlines the importance of getting back to analyses as an initial reaction.

[...] At the end of each training interview, I ask a trainee to make a repetition of the training. If he fails, I help him. Personally, I urge my trainees to find solutions as my role is to guide them. The fact that the trainee becomes aware of the magnitude of his responsibility is in itself a success. (Hedy, lines 33 - 36)

Karima reveals to us that a difficulty does not really have much incidence on the training given that the teacher-students are in a stage of learning. Through these after-session interviews, Aymen perceives the reasons for which the session did not work, he attempts to catch up and do things better next time. For him, comm-unication is the basis of success. It is, therefore, important to discuss things together and try to find solutions.

[...] It is the teacher-student's duty to suggest an efficient regulation and it is mine to guide him to the path of success. (Karima, line 29 - 30)

[...] We try to discuss gaps and then we work together in search of reasonable solutions (Aymen, line 27 - 28)

Concerning the teacher-student's errors, all our cooperative teachers agree to say that an error is not fatal but rather a chance for the learner to improve (Altet, Paquay, \& Perrenoud, 2002). Indeed, cooperative teachers should tolerate that his teacher-student is not perfect since he is on training. Thus, we can state that our cooperative teachers are active actors in the training of teacher-student. (Py et Leduc-Claire, 2008). However, these latter should equally agree on the fact that a persistent difficulty or error can have an incidence on the training.

\subsection{Interviewing the Teacher-Student}

Marwa generally uses an explanatory interview after the PE session to clarify things with the teacher-student(s). For example, she asks the Teacher-student to explain why he used such an objective for such a pedagogical situation. Aymen prepares his questions in advance on the basis of his observations. Hedy tries to use an explicit interview but admits having difficulties with hiding his emotions as well as his inability to guide the Teacherstudent to good answers. Karima thinks about using an explanatory interview all the time. She does so, for example, when she asks the teacher-student about the objective of a given activity. Her interviews are more frequent in the first sessions of the training.

[...] It is important to discuss with the teacher-student. Then, we will manage to find something relevant together (Marwa, line 41 - 42)

[...] I think that I am at the teacher-student's disposal, we discuss issues together then we choose strategies to move forward (Aymen, line 37 - 38)

[...] We check together whether our functioning models are convenient for us or not. We set our schedule, our ways of working together. (Hedy, line 36 - 37)

Not all our cooperative teachers have the same vision of explanatory interview. All of them think of using it, even if it does not correspond exactly to the definition of Vermersch (1994). Marwa uses it to analyze the sessions. Aymen starts from a precise point and takes note of what the teacher-student says.

Hedy has well understood the meaning of this approach since he admits finding difficulties to stick to the facts only. For Lotfi, this method consists simply in asking questions to the teacher-student to make him apply a self-evaluation on his work. We notice then that this method is rather unclear for our cooperative teachers. 


\section{Conclusions}

Through this research, our objective consisted in perceiving the dominating roles that the Tunisian cooperative teachers attribute to the development of teacher-students' professional skills. The results show that cooperative teachers have a rather common vision towards the importance of accompaniment roles despite the reduced sieze of the sample as well as the exploratory character of our study which do not allow to generalize the results.

Concerning the role that cooperative teachers think of assuming, the respondents are fully aware of the link existing between teaching quality and students' learning. All of them also agree on the fact that error, as long as it does not persist, is an opportunity to improve. All of hem consider that each teacher-student has his own personality and we must therefore adapt our comments to each one of them. Finally, each one of us should try to encourage his teacher-students to put the link between theory and practice when they analyze their teaching.

Our study has brought to light five essential roles of the cooperative teacher in initial training: 1) Checking the quality of course planning provided by the teacher-student; 2) observing the teacher-student; 3) urging the teacher-student to assume his responsibility and ponder on the teaching task; 4) supporting the teacher-student to find a solution in case of difficulty or bad progress of a session; and 5) establishing a dialogue with the teacher-student in the framework of a clarification interview.

The respondent cooperative teachers have, however, reckoned that cooperative should take another trend, more centered on the development of the Teacher-student's capacities than on the control of his actions. They consider that pedagogical accompaniment is a process which consists in observing the trainee student in situation and helping him at the level of class management, session preparation, etc. In order to assess the accompaniment work. It is important, according to some respondents, to establish a confidence relationship which is the basis of all support. These statements support the opinion of Acheson \& Damien Gall (1993): "In order to be efficient, supervision requires a high level of confidence.” (p. 411).

Finally, considering that our research has allowed to better understand how cooperative teachers conceive their accompaniment roles, we contemplate, in continuity of the work, to allocate more time and better opportunities for teacher-students and supervisors as well in order to collect their perceptions on the cooperative teacher's role in the training of future PES teachers and their own contribution in the process.

\section{References}

Acheson, K. A., \& Gall, M. D. (1993). Pedagogical Supervision. Methods and Secrets, 44, 7-16.

Altet, M., Paquay, L., \& Perrenoud, P. (2002). Teacher Educators: What Professional? Bruxelles: Superior Boeck.

Arrighi, G. (1983). The Labor Movement in Twentieth-Century Western Europe. In I. Wallerstein (Ed.), Labor in the World Social Structure. London: Sage.

Bali, N. (2005). Articulation "Theory and Practice” in the Training of Tunisian Student Teachers of Physical Education: Conceptions of Trainers and Trained. Research and Training, 49, 135-150.

Baribeau, C. (2009). Data Analysis Group Interviews. Qualitative Research, 28, 133-148 .

Belton, S., Woods, C., Dunning, C., \& Meegan, S. (2010). The Evaluation of a Cooperating Physical Education Teachers Programme (COPET). European Physical Education Review, 16, 141-154. http://dx.doi.org/10.1177/1356336X10381302

Bennour, N. (2013). Teaching Skills Student Interns EPS. France: European Editions Universitaires.

Boudreau, A. (2009). The Construction of Linguistic Representations: The Case of Acadia. The Canadian Journal of Linguistics, 54, 439-459. http://dx.doi.org/10.1353/cjl.0.0054

Boudreau, P. (2001). What Is Happening in a Successful Internship? Review of Educational Sciences, 27, 65-84.

Bower, G. G., \& Bonnett, S. (2009). The Examination of a Mentoring Relationship During a Metadiscrete Physical Education Field Experience. The ICHPER-SD Journal of Research in Health, Physical Education, Recreation, Sport \& Dance, 4, 19.

Chaliès, S., Ria, L., Bertone, S., Trohel, J., \& Durand, M. (2004). Interactions between Preservice and Cooperating Teachers and Knowledge Construction during Post-Lesson Interviews. Teaching and Teacher Education, 20, 765-781. http://dx.doi.org/10.1016/j.tate.2004.09.001

Charlier, B. (1998). Learn and Change Their Teaching Practice: Teaching Experiences. Belgium: De Borck University.

Clerc, I. (1998). The Teaching of Professional Writing in Academia. In C. Préfontaine, L. Godard, \& G. Fortier (Eds.), To Better Understand the Reading and Writing: Teaching and Learning (pp. 345-370). Montreal: Logic Publishing.

Correa Molina, E. (2008). Internship Supervisors: Qualities for a Trainer Role. In E. Correa Molina, C. Gervais, \& S. Ritter- 
shaussen (Eds.), International Explorations: Towards a Conceptualization of Internship Experiences. Sherbrooke: Éditions du CRP.

Deaudelin, C., Lefebvre, S., Brodeur, M., Mercier, J., Dussault, M., \& Richer, J. (2005). Changing Practices and Conceptions of Teaching, Learning and ICT in Primary School Teachers in Professional Context. Review of Education, 31, 79-110.

Desbiens, J. F., Borges, C., \& Spallanzani, C. (2009). Invest in Training Teachers Individuals Associated to the Teaching Course a Professional Development Tool. Éducation et Francophonie, 37, 6-25. http://dx.doi.org/10.7202/037650ar

Desbiens, J. F., Spallanzani, C., \& Borges, C. (2013). When Teaching Internship Awry. Québec: University Press of Quebec.

Dodds, P. (1985). Are Hunters of the Function Curriculum Seeking Quarks or Snarks? Journal of Teaching in Physical Education, 4, 91-99.

Durand, M. (2000). The Child and Sport. France: French Presses University.

Fenstermacher, G. D. (1979). Educational Accountability: Features of the Concept. Theory into Practice, 18, 330-335. http://dx.doi.org/10.1080/00405847909542854

Gervais, C., \& Desrosiers, P. (2005). The School, a Place of Teacher Training: Issues and Guides to Accompany Trainees. Quebec City: Presses Université Laval.

Gohier, C., Bouchard, Y., Anadon, M., Charbonneau, B., \& Chevrier, J. (2002). Professional Identity Teacher When He Is Trainer Masters Rupture or Continuity? In S. Baillauquès, Mr. Lavoie, M. L. Chaix, \& J. C. Hétu (Eds.), Identity among Teacher Educators. Franco-québois Exchanges (pp. 195-215). Paris Harmattan.

Guyton, E. (1989). Guidelines for Developing Educational Programs for Cooperating Teachers. Action in Teacher Education, 11, 54-58. http://dx.doi.org/10.1080/01626620.1989.10462738

Guyton, E., \& McIntyre, D. J. (1990). Student Teaching and School Experiences. In W. R. Houston (Ed.), Handbook of Research on Teacher Education (pp. 514-534). New York: Macmillan.

Locke, R. R. (1984). The End of the Practical Man: Entrepreneurship and Higher Education in Germany, France, and Great Britain, 1880-1940 (Vol. 7). Amsterdam: Elsevier Science.

Martin, D. (2002). Pentecostalism: The World Their Parish (p. 10). Oxford: Blackwell.

Metcalf, D. (1991). Control of Granulocytes and Macrophages: Molecular, Cellular, and Clinical Aspects. Science, 254, 529-533. http://dx.doi.org/10.1126/science.1948028

Nichols, D. S. (2011). Essentials of MMPI-2 Assessment (Vol. 88). Hoboken, NJ: John Wiley \& Sons.

Pelpel, P. (2003). Welcome, Accompany, Train Teachers. Social Stories.

Peterson, S. M., Valk, C., Baker, A. C., Brugger, L., \& Hightower, A. D. (2010). "We’re Not Just Interested in the Work”: Social and Emotional Aspects of Early Educator Mentoring Relationships. Mentoring \& Tutoring: Partnership in Learning, 18, 155-175. http://dx.doi.org/10.1080/13611261003678895

Petignat, P. (2008). Do the Courses Development Skills? Paper Presented at the Symposium HEP Lausanne-UQTR, Trois-Rivières, Quebec.

Portelance, L. (2010). Analysis of Perceptions of the Support of a Teacher Associated with the Training of the Trainee. Éducation et Francophonie, 38, 21-38. http://dx.doi.org/10.7202/1002162ar

Rousseau, N., Courcy, M., \& Boutet, M. (2002). Are the Teachers Involved in Special Education Loans to the Establishment of a Probation Supervision Model in the Context of a Transfer of Responsibility of the University to the School? The Journal of Educational Thought (JET)/Revue de la Pensée Educative, 36, 129-148.

Shulman, L. S., \& Lanier, J. E. (1977). The Institute for Research on Teaching: An Overview. Journal of Teacher Education, 28, 44-49. http://dx.doi.org/10.1177/002248717702800413

Tannehill, D., \& Zakrajsek, D. (1988). What's Happening in Supervision of Student Teachers in Secondary Physical Education. Journal of Teaching in Physical Education, 8, 1-12. 


\section{Submit or recommend next manuscript to SCIRP and we will provide best service for you:}

Accepting pre-submission inquiries through Email, Facebook, Linkedin, Twitter, etc A wide selection of journals (inclusive of 9 subjects, more than 200 journals)

Providing a 24-hour high-quality service

User-friendly online submission system

Fair and swift peer-review system

Efficient typesetting and proofreading procedure

Display of the result of downloads and visits, as well as the number of cited articles

Maximum dissemination of your research work

Submit your manuscript at: http://papersubmission.scirp.org/ 